American Journal of Pharmaceutical Education 2017; 81 (7) Article 5925.

\title{
RESEARCH
}

\section{Curriculum in Psychiatry and Neurology for Pharmacy Programs}

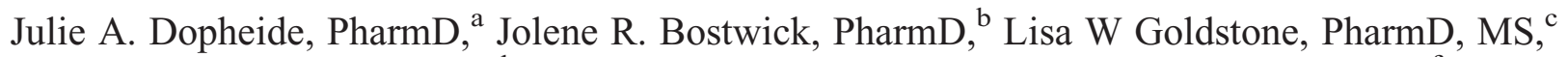

Kelan Thomas, PharmD, MS, ${ }^{\mathrm{d}}$ Ruth Nemire, PharmD, EdD, ${ }^{\mathrm{e}}$ Kelly N. Gable, PharmD, ${ }^{\mathrm{f}}$

Marshall Cates, PharmD, ${ }^{\mathrm{g}}$ Joshua Caballero, PharmD, ${ }^{\mathrm{h}}$ Tawny Smith, PharmD, ${ }^{\mathrm{i}}$

Jacquelyn Bainbridge, PharmD ${ }^{\mathrm{j}}$

${ }^{a}$ University of Southern California School of Pharmacy and Keck School of Medicine, Los Angeles, California

${ }^{\mathrm{b}}$ University of Michigan College of Pharmacy, Ann Arbor, Michigan

${ }^{\mathrm{c}}$ University of Southern California School of Pharmacy, Los Angeles, California

d Touro University California College of Pharmacy, Vallejo, California

e American Association of Colleges of Pharmacy, Alexandria, Virginia

${ }^{\mathrm{f}}$ Southern Illinois University Edwardsville, Edwardsville, Illinois

${ }^{g}$ Samford University McWhorter School of Pharmacy, Birmingham, Alabama

${ }^{\mathrm{h}}$ Larkin University College of Pharmacy, Miami, Florida

${ }^{\mathrm{i}}$ The University of Texas at Austin Dell Medical School, Austin, Texas

${ }^{\mathrm{j}}$ University of Colorado Skaggs School of Pharmacy and Pharmaceutical Sciences and School of Medicine, Anschutz Medical Campus, Aurora, Colorado

Submitted July 10, 2016; accepted January 18, 2017; published September 2017.

Objective. To describe pharmacy curricula in psychiatry and neurology and to report on neuropsychiatric pharmacy specialists' views on optimal curriculum.

Methods. Design and administer one electronic survey to accredited pharmacy programs asking them to report information on curricula in psychiatry and neurology for the 2014-2015 academic year. Design and administer a separate electronic survey to board certified pharmacists with an academic affiliation who are members of the College of Psychiatric and Neurologic Pharmacists (CPNP) asking about their teaching activities and their opinion on optimal curricula.

Results. Fifty-six percent of pharmacy programs and $65 \%$ of CPNP members responded to the surveys. The program survey revealed greater than $80 \%$ of topics were taught by full-time faculty. Didactic lecturing, teambased learning, and case studies were the most common teaching methods. Programs dedicated the most didactics (3 to 5+ hours) to epilepsy, depression, schizophrenia, substance use disorders, and pain. Autism, traumatic brain injury, personality, and eating disorders were either not taught or given $\leq 1$ hour of didactics in most programs. Inpatient psychiatry had the most APPE placements with a mean of 19.6, range 0-83. APPE electives in psychiatry outnumbered those in neurology 5 to 1. CPNP member survey results showed 2 out of 3 members agreed that curriculum could be improved with additional APPEs in psychiatry and neurology.

Conclusion. Didactic hour distribution in psychiatry and neurology could be improved to better align with board certification in psychiatric pharmacy (BCPP) recommendations and disorder prevalence and complexity. Specialists recommend an experiential component in neurology and psychiatry to combat stigma and improve pharmacist knowledge and skills.

Keywords: curriculum, pharmacy, psychiatry, neurology, recommendations

\section{INTRODUCTION}

In the United States, approximately 1 in 4 individuals suffer from a psychiatric diagnosis and 1 in 5 suffer from a neurologic condition. ${ }^{1,2}$ Collectively, these neuropsychiatric

Corresponding Author: Julie A. Dopheide, University of Southern California School of Pharmacy and Keck School of Medicine, 1985 Zonal Ave., Los Angeles, CA 90089. Tel: 323-442-1454. E-mail: dopheide@usc.edu disorders are the number one cause of disability in the United States, surpassing cardiovascular disease. ${ }^{3}$ Neuropsychiatric disorders are also among the top 5 most costly disorders in the US, on par with cancer. ${ }^{4}$ In his 2013 testimony to Congress calling for increased mental health care funding, Dr. Thomas Insel, the National Institute of Mental Health (NIMH) medical director, reported the United States spends $\$ 317$ billion annually on psychiatric disorders when considering 


\section{American Journal of Pharmaceutical Education 2017; 81 (7) Article 5925.}

direct health care expenditures and indirect costs including loss of productivity. ${ }^{5}$ Neurologic conditions such as migraine, are among the most debilitating and costly of all chronic conditions. Direct costs for migraine treatment were found to be $\$ 2,571$ per person per year higher than persons without migraine who suffer from other chronic conditions. ${ }^{6}$ The cost of neuropsychiatric disorders is high but research shows that diagnosis and treatment can improve health outcomes and decrease costs. A 2016 global return on investment (ROI) analysis showed significant value in treating depression and anxiety with an ROI of 3-6 to 1, in dollars saved through improved productivity and health outcomes. ${ }^{7}$ Recognizing the societal impact of one of the most common neuropsychiatric disorders, depression, the U.S. government published 2016 recommendations calling for widespread depression screening and referral for accurate diagnosis and treatment in persons aged 12 and above. ${ }^{8,9}$

Pharmacists require knowledge and skills in recognizing and treating these common and costly disorders, but the breadth and scope of education provided by pharmacy programs in the US remains largely unknown. The need to describe, evaluate and share knowledge of pharmacy curriculum is timely given the number of accredited programs offering a PharmD in the US has nearly doubled from 72 to 135 between 1987 and $2015 .^{10}$ Pharmacy curriculum recommendations exist for several therapeutic areas including oncology, pharmacogenomics, pediatrics, geriatrics, and substance abuse, but not psychiatry and neurology. ${ }^{11-15}$ In order to develop recommendations for optimal curriculum in psychiatry and neurology for pharmacy programs, the College of Psychiatric and Neurologic Pharmacists (CPNP) created a task force comprised of pharmacists with expertise in psychiatry and neurology, from diverse geographic regions and from both public and private academic programs. Curriculum design and curriculum committee experience of the task force members include four members with $\geq 20$ years of experience, four members with 10 to 19 years of experience, and two members with less than 10 years of experience. Members of the task force were charged with describing current curriculum in psychiatry and neurology and recommending optimal curriculum. The American Association of Colleges of Pharmacy (AACP)'s academic affairs division collaborated with CPNP through active participation and by providing information on accredited pharmacy programs (eg, contacts, size, year of inception).

Rationale for including both psychiatric and neurologic disorders in this report included an alignment with CPNP's mission "to advance the reach and practice of psychiatric pharmacists." In addition, the pathophysiology and treatment of both psychiatric and neurologic disorders involve brain mechanisms and evaluation of behavior and motor features. ${ }^{16}$ Dementia is an example of a diagnosis which presents with both neurologic and psychiatric features, making categorization challenging. Using the term "neuropsychiatric disorders" to describe both psychiatric and neurologic disorders has been encouraged by some psychiatrists and neurologists as a way to realign these central nervous system disorders. ${ }^{16}$ Such realignment may be associated with positive outcomes as discussed by White and colleagues, including reduced discrimination for individuals living with psychiatric disorders and narrowing the mortality gap in patients with serious mental illness. ${ }^{17}$ Indeed, the NIH recognizes psychiatric and neurologic disorders collectively as "neuropsychiatric disorders" when reporting disability adjusted life years (DALYs) associated with chronic diseases. ${ }^{3,4}$

\section{METHODS}

There were two separate surveys developed by the task force. The first electronic survey was designed to assess the neuropsychiatry curriculum in clinical therapeutics in pharmacy programs during the 2014-2015 academic year. Faculty involved in curriculum at pharmacy programs were asked to report their credentials and practice sites, hours of instruction, Introductory Pharmacy Practice Experiences (IPPEs), Advanced Pharmacy Practice Experiences (APPEs), skills taught, and instructional methods utilized. A second electronic survey asked CPNP members with board certification in psychiatric pharmacy and an academic affiliation to describe their own teaching involvement. They were also asked to provide recommendations on what should be taught in therapeutics of neuropsychiatric curriculum of pharmacy programs (eg, hours of instruction, IPPEs, APPEs, clinical skills). Items on curricular assessment were not included to keep survey length in check. Curricular content and teaching methodology were the focus of this investigation.

Both surveys were developed with input from the task force, CPNP board of directors, AACP academic affairs staff, and field testers. Ten CPNP members field tested both electronic surveys for content and clarity. Field testers included four experienced academicians ( $\geq 20$ years in academia), four mid-career individuals (10-19 years in academia) and two newer academicians ( $\leq 9$ years in academia).

This input was used to further refine both surveys that were electronically administered late quarter 2015; closing December 2015. With a survey completion goal of $75 \%$, participants received survey reminders both electronically and personally from task force members. Both surveys were approved by the University of Southern California's (USC) Institutional Review Board. The task 


\section{American Journal of Pharmaceutical Education 2017; 81 (7) Article 5925.}

force analyzed de-identified data from both surveys, conducted a literature review on curricular issues, and considered the Accreditation Council for Pharmacy Education's (ACPE) 2016 accreditation standards in this report.

USC's statistician used SAS version 9.4 (Cary, NC) with an alpha of .05 to compare survey responses. Pharmacy program faculty responses were compared by size of graduating class (1-99 vs 100 or greater) and age of pharmacy program (first graduating class pre-1990 vs. 1990-present). Member survey responses were compared by age ( $\leq 35$ years or $>35$ years old), board certification year (pre-2005, 2005-2010, 2011-2015), and status of employer (academic institution vs. health system).

\section{RESULTS}

Fifty-six percent (75/133) of program faculty submitted survey data. A survey was considered complete if $>85 \%$ of data on faculty credentials, didactic hours, and experiential learning was provided. The survey sample was representative of pharmacy programs in the US given responders and non-responders were similar with regard to geographic region (Northeast, Midwest, South, and West), $[p=.84]$, public/private status $[p=.75]$, class size $\leq 99$ or $\geq 100[p=.85]$ and age (pre-1990 or post$1990[p=.32]$ ) using Chi squared test. Greater than $80 \%$ of therapeutics topics were taught by full-time clinical faculty defined as "faculty engaged in practice-based teaching." Clinical faculty teaching topics in psychiatry usually had board certification in psychiatric pharmacy (BCPP) (45\%-77\%), while board certification in pharmacotherapy (BCPS) was more common for neurology topics $(37 \%-73 \%)$ since there is no specific credential for neurology (Figure 1).

The certified geriatric pharmacist credential (CGP) was held by $<10 \%$ of faculty for most neuropsychiatric topics, but exceptions included pain (10.7\%), Parkinson's disease $(26.7 \%)$, and dementia (32\%) as the topics with relatively higher percentages of faculty holding the CGP credential.

Faculty from the 75 programs who responded to the survey indicated neuropsychiatric topics were most frequently taught in the $\mathrm{P} 3$ year for $64 \%$ of programs, while $43 \%$ of the programs include this content in the $\mathrm{P} 2$ year. Very few covered this material during the P1 year (13\%). On average, programs devoted $\geq 3$ hours to pain ( 3.4 hours) and epilepsy (3.4 hours) among neurology topics, while depression (3 hours) and schizophrenia (3 hours) were the highest averages among the psychiatry topics (Figure 2 ). Of note, the majority of programs reported no lecture time for personality disorders (69\%), autism spectrum disorder (65\%), traumatic brain injury (59\%), and eating disorders $(51 \%)$ despite these conditions potentially affecting an individual throughout his or her lifespan.

Programs varied greatly in terms of the number of APPE slots offered during the 2014-2015 academic year.

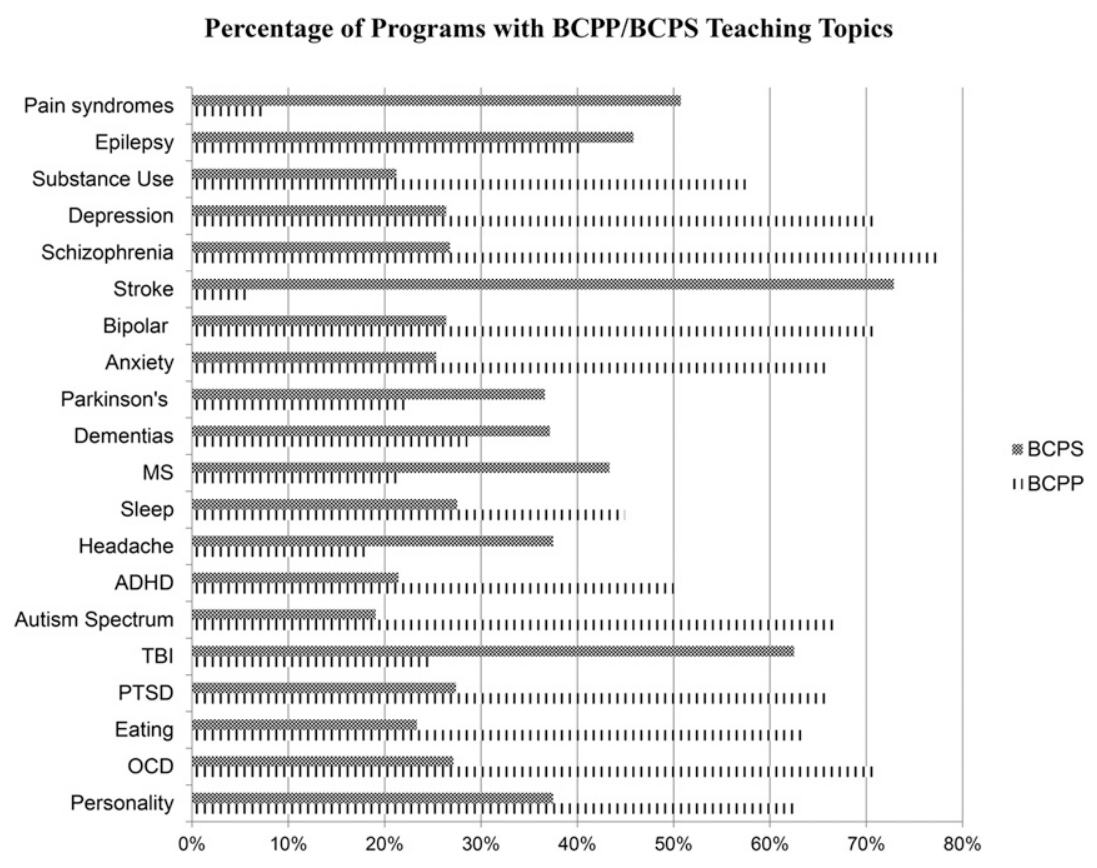

Figure 1. Topics taught by BCPS and BCPP faculty. Includes data from 75/133 programs. The X-axis lists the percentage of board certified pharmacists who reported teaching neuropsychiatric topics in clinical therapeutics and the Y-axis lists the neuropsychiatric topics taught. 


\section{American Journal of Pharmaceutical Education 2017; 81 (7) Article 5925.}

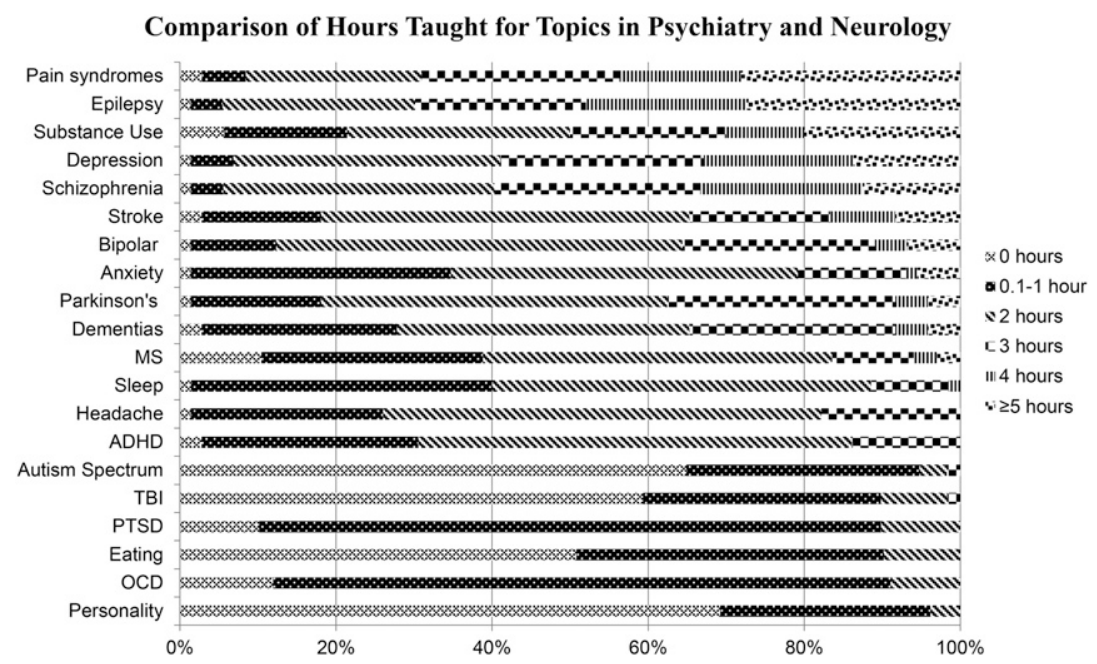

Figure 2. Number of reported hours of didactic instruction per topic. Represents data from 75 out of 133 pharmacy programs. Multicolored bars across the $\mathrm{X}$-axis compare the mean percentage of time devoted to teaching didactic clinical therapeutics in psychiatry and neurology for each topic listed on the Y-axis.

Available APPE placements in psychiatry outnumbered those available in neurology by 5 to 1 . Acute inpatient psychiatry placements $(52.9 \%)$ were the most common type of neuropsychiatric APPE followed by geriatric psychiatry $(19 \%)$ and ambulatory psychiatry (18.9\%). Fewest opportunities for APPEs existed for pediatric psychiatry, forensic psychiatry, and ambulatory neurology. For programs with available psychiatry and neurology APPE rotations, the number of potential placements that went unfilled were 231 in psychiatry and 52 in neurology for the 2014-2015 academic year. It was not possible to calculate the average of unfilled APPE placements due to the variability of placement opportunities within programs and variability of responses. For example, out of 72 distinct program responses regarding APPEs in psychiatry, 29 reported "0" unfilled APPEs, 18 selected "unknown," with the remaining responses varying from 1 to 30 unfilled psychiatric APPEs. Out of 66 distinct program responses regarding APPEs in neurology, 27 reported " 0 " unfilled APPEs, 25 selected "unknown," with the remaining responses varying from one to seven unfilled neurologic APPEs. IPPE placements in psychiatry and neurology were too limited to include in this report.

The majority of preceptors for APPEs who held board certification were BCPP with the exception of the acute care inpatient neurology rotation in which BCPS certification outnumbered BCPPs ( $20 \%$ vs $6.7 \%)$. Pharmacy residents were also involved in teaching psychiatry APPEs (PGY1 22.7\%; PGY2 26.7\%) and neurology APPEs (PGY1 9.3\%; PGY2 6.7\%). Fifty-four percent of programs offered student-driven research projects in psychiatry or neurology, while $48 \%$ offered interprofessional education in neuropsychiatry.

The pharmacy program survey asked respondents to describe how neuropsychiatric content was taught in the 2014-2015 curriculum, including any content delivered outside of a therapeutics course (eg, lecture, case conference, performance-based laboratories). Didactic lecturing, team-based learning, and case-study activities were the most common teaching methods reported. Among the 77 free-text responses, approximately $65 \%$ of programs reported lecture to be the primary method of content delivery within their program. With that said, two-thirds of respondents reported these lectures coincided with case discussions and/or concurrent practical lab sessions. Notably, nine programs reported almost exclusively utilizing lectures to deliver neuropsychiatric content. Slightly more than one-third of respondents indicated utilizing team-based learning (TBL), problem-based learning (PBL), or integrated, case-based team-taught methods for content delivery. Most commonly, TBL was combined with some other method, including lecture, laboratory, cases, or a patient panel. Resident teaching involvement most often consisted of presenting didactic lectures with some participation in case-based and TBL.

Types and number of APPE offered were compared across all programs by calculating an APPE ratio. The APPE ratio was calculated by dividing the number of each type of APPE available (eg, acute care psychiatry or acute care neurology) by the size of the graduating class in 2014. Comparisons of APPE ratios between all offerings in psychiatry and neurology show 1 out of every 5 students had an opportunity to select an APPE in psychiatry 


\section{American Journal of Pharmaceutical Education 2017; 81 (7) Article 5925.}

whereas only one in 20 students had the opportunity to select an APPE in neurology. Psychiatry APPE offerings were significantly more plentiful than neurology APPE offerings $(p<.0001)$ according to Wilcoxon signed rank sum test. Acute care psychiatry APPEs were four times more prevalent than ambulatory care psychiatry APPEs $(p<.0001)$ using Wilcoxon signed rank sum test (nonparametric version of a paired sample $t$-test). There were no statistical differences in the APPE ratio or between psychiatry and neurology APPEs based on age of school (first graduating class before 1990 vs. 1990 or after) or class size (1-99 vs $100+)$.

There were 173 out of $267(64.8 \%)$ respondents to the member survey comprised of $17 \%$ tenure-track faculty, $31 \%$ non-tenure track and $39 \%$ of members with adjunct/affiliate status. A survey was considered complete if $>80 \%$ of the content was completed. The majority of respondents were assistant professors (31\%), followed by associate professors $(25 \%)$, and full professors (16\%); the rest were clinical instructors or research faculty. Nineteen percent reported teaching at multiple pharmacy programs. The majority were practicing at government-funded medical centers, including VA and non-VA facilities (40\%). Approximately $81 \%$ of respondents agreed that students received adequate instruction in pharmacology/ chemistry before therapeutics coursework. Regarding didactics in therapeutics, $74 \%$ agreed there were sufficient faculty qualified to teach psychiatry, while only $50 \%$ felt their institution had enough qualified faculty to teach neurology.

Members were more likely to be involved in experiential teaching 123/173 (71.9\%) compared to classroombased teaching 103/169 (60.9\%) and experiential teaching was more often reported in psychiatric vs. neurologic practice settings (Figure 3). Respondents were much more likely to be involved with APPE than IPPE psychiatry experiences with $88.7 \%$ precepting at least one APPE student (range of 1-30). There were no neurology IPPEs reported and few members $(\mathrm{N}=5)$ were involved in precepting APPE students in neurology. Textbooks, journal articles, and the DSM-5 were the most commonly required reading materials for APPEs in psychiatry and neurology.

Most respondents recommended 3 hours of therapeutics for schizophrenia, depression and epilepsy; 2 hours for Parkinson's disease, stroke, dementia, headache, pain syndromes, bipolar, anxiety, sleep, and substance use disorders; and 0.1-1 hour for multiple sclerosis, traumatic brain injury, autism spectrum, obsessive compulsive, posttraumatic stress, attention-deficit/hyperactivity, personality, and eating disorders (Figure 4). These recommendations were consistent with the average hours per topic reported in the program survey. The main discrepancies between hours taught and teaching hours recommended were for topics not taught by more than half of the programs, such as autism spectrum, eating disorders, personality disorders, and traumatic brain injury. Between 50 to $70 \%$ of responding members recommended that these topics should be taught for 0.1-1 hour, indicating these topics should be considered for increased didactic instruction time in neuropsychiatry curricula.

There were some differences to which clinical skills members "recommended" and which skills they were teaching in APPEs (Figure 5). Comments did not reveal potential reasons for this discrepancy. Nearly all responding members (98\%) suggested that mental status exam should be taught, $96 \%$ for side effect monitoring scales, $94 \%$ for motivational interviewing, $92 \%$ for shared decision making, $89 \%$ for neurological exam, and $87 \%$ for psychiatric rating scales, yet only between $30 \%$ and $75 \%$ reported teaching these skills. Eighty percent suggested a first-person account from a consumer or National Alliance on Mental Illness (NAMI) member should be covered in the curriculum. Therapeutic textbooks and DSM-5 were the most commonly required reading materials for neuropsychiatry topics, with $73 \%$ of members reporting them as required for therapeutic courses and $48 \%$ for neuropsychiatry APPEs.

Distribution or sharing the teaching load among faculty appeared to be somewhat more common in neurology, compared to psychiatry with more than $60 \%$ of respondents reported share the didactic teaching load for topics related to epilepsy, multiple sclerosis, Parkinson's disease, dementia, stroke, pain syndromes and headache whereas only $40 \%$ to $60 \%$ reported sharing the teaching load for topics in psychiatry such as depression, bipolar disorder, schizophrenia, eating disorders, personality disorders, autism spectrum disorder and anxiety-related disorders. More faculty teaching neurology had BCPS certification which may be indicative of a shared teaching load.

Members were asked to comment on other instructional components for psychiatry and neurology. Comments revealed three major elective classes offered in neurology, psychiatry, and drugs of abuse. Psychiatry electives were mentioned 15 times, and covered a wide range of disorders from electroconvulsive therapy (ECT) to mood disorders. Neurology electives were mentioned eight times and drugs of abuse electives were mentioned six times. Psychiatry cases were taught using an "integrated approach" in an "interdisciplinary setting" according to comments from three members. One respondent said that they "believed these topics should be stressed in PGY2 residencies, not in pharmacy schools." 


\section{American Journal of Pharmaceutical Education 2017; 81 (7) Article 5925.}

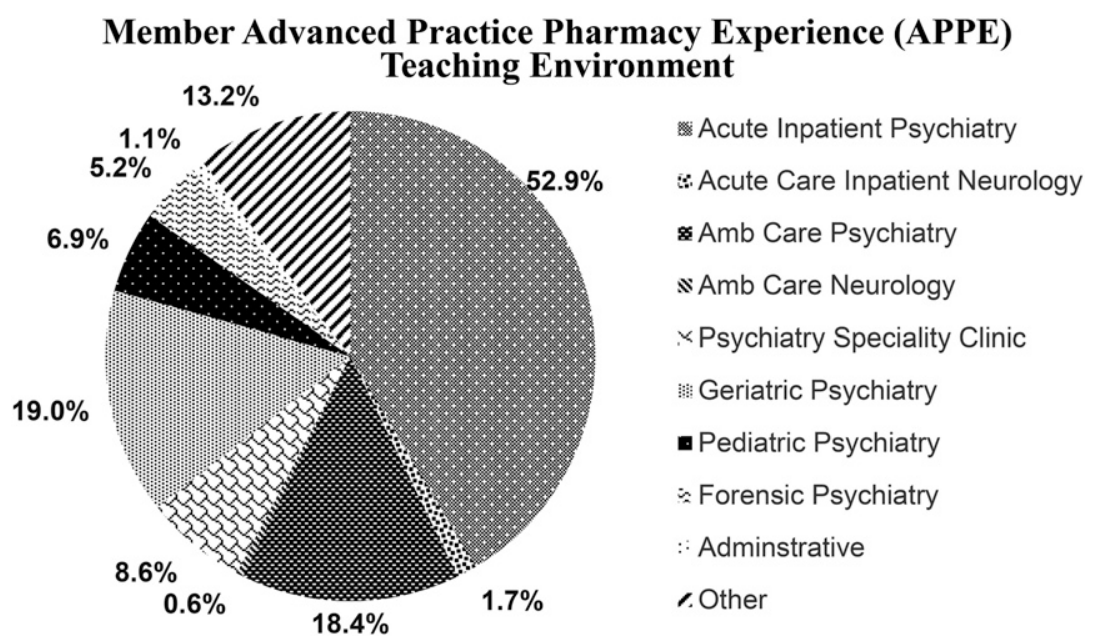

Figure 3. Depicts the APPE teaching environment/setting reported by members. Acute care inpatient psychiatry was the most common clinicial environment followed by geriatric psychiatry, and ambulatory care psychiatry. Acute care inpatient neurology was the most commonly reported neurology teaching environment.

There was no statistical difference in the distribution of types of APPEs reported by members based on their age or year of board certification. Those newly board certified in psychiatric pharmacy (2011-2015) were significantly more likely to be teaching APPEs in inpatient psychiatry compared to those who first certified before 2005 $(p<.0001)$. In addition, a positive association was found between age ( $>35$ years old) and teaching acute care inpatient psychiatry $(p=.01)$ by Chi-squared analysis. This seemingly contradictory finding appears due to greater numbers of survey respondents under age 35 who certified between 2005 and 2010 and reported teaching in clinic settings.

\section{DISCUSSION}

Results from both program and member surveys provide information on the current status of clinical didactic and experiential education in psychiatry and neurology at pharmacy programs in the United States during the 2014-2015 academic year. Survey results, educational literature, and ACPE 2016 accreditation standards were utilized by members of the curriculum paper task force to develop curricular recommendations for psychiatry and neurology discussed in the following sections.

Faculty are teaching a broad range of didactics and experiential components (Figures 1 and 3). Disorder prevalence and the likelihood of pharmacist interaction should

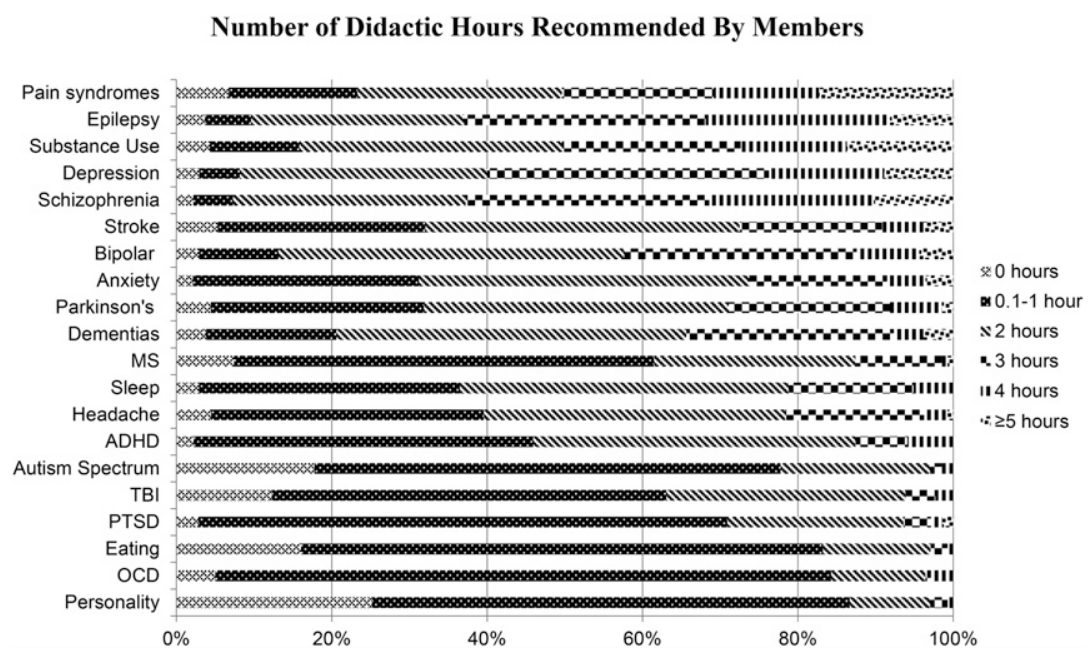

Figure 4. Specialist recommendations for hours taught by neuropsychiatric topic. Depicts member recommendations for the relative amount of didactic hours that should be allotted to each therapeutics content area in the pharmacy curriculum. The Y-axis lists the content area and the $\mathrm{X}$-axis lists the mean percentage of time recommended by members. 


\section{American Journal of Pharmaceutical Education 2017; 81 (7) Article 5925.}

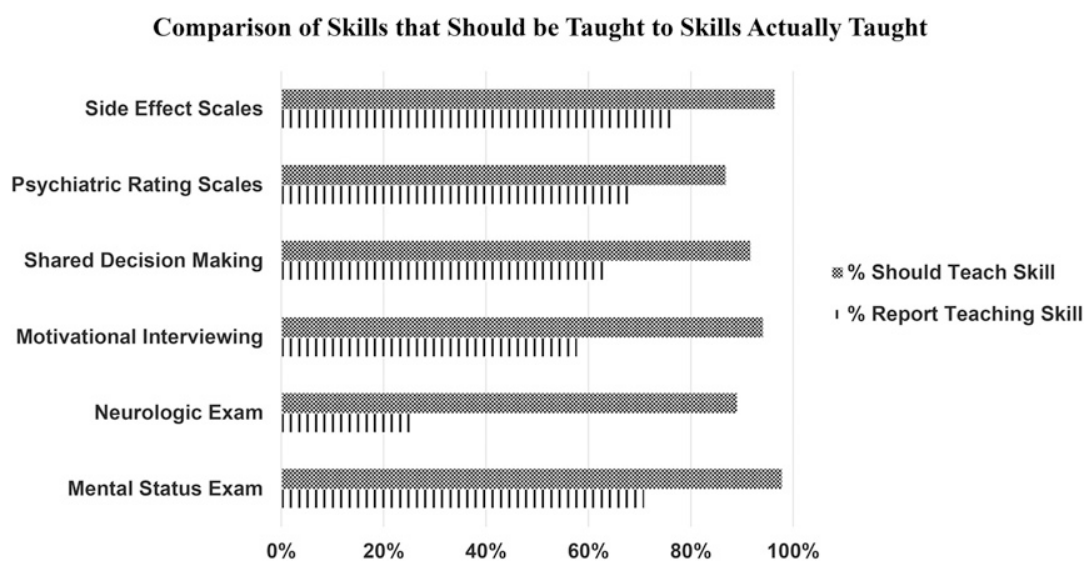

Figure 5. Skills applicable to neuropsychiatric pharmacy practice. Represents members' views on skills that should be taught in pharmacy schools compared to skills they actually teach in the curriculum of their pharmacy program. Members were given the list of skills displayed on the Y-axis and asked to respond "yes" or "no" with regard to "should be taught" or "is taught." The X-axis shows the percentage of responders. Approximately 130 of 173 members responded although the absolute number of responses for each skill varied.

be considered when assigning didactic hours. In most cases, programs reported devoting more instruction time to more common disorders (eg, depression, epilepsy, pain) where pharmacist interaction time is considerable. Exceptions were autism spectrum disorder, traumatic brain injury, and eating disorders, which were not taught at all in some pharmacy programs despite being present in at least $1 \%$ of the population. However, it is possible these topics were covered within broad therapeutic areas such as "Pediatric Psychotherapeutics" for autism spectrum disorder, or "Introduction to Psychiatry" for personality disorders. Of note, pharmacy programs devoted significantly more time to schizophrenia and Parkinson's disease even though the prevalence for these disorders is estimated between $0.5 \%$ and $1 \% .^{1,2,18}$ The significance of drug therapy in treatment, high morbidity and mortality, and program faculty preference or expertise are additional factors that likely influenced instructional time allotment.

Over the past decade, pharmacy programs appear to be employing more interactive teaching methods for delivering neuropsychiatric content. Program survey comments on teaching methods revealed a majority of programs rely on a combination of lectures, case conferences, problembased teaching, or TBL to deliver didactic content. Approximately $15 \%$ reported teaching neuropsychiatric content exclusively through traditional lectures. This contrasts with the 2007 report from Cates and colleagues stating approximately $75 \%$ of therapeutics content in psychiatry was delivered by lecture format with $25 \%$ delivered through case-based learning approaches. ${ }^{20}$ Team-based learning and case conferences were among the most commonly used interactive teaching methods according to our 2015 survey. $^{21}$
Multiple sources highlight the issue of social distance, stigma, and its impact on pharmacy students' perspectives on individuals living with mental illnesses such as schizophrenia or neurologic conditions such as epilepsy. ${ }^{22-25}$ Stigma has been shown to negatively impact care for both psychiatric and neurologic conditions. ${ }^{22-25}$ Health care professional students report feeling uncomfortable interacting with a person with a severe mental or neurological condition, reporting that "it is difficult to know how to talk to them or their families. ${ }^{, 22-25}$ Addressing these issues is paramount to ensure students are best prepared to provide quality care for this population. While direct contact with patients and families has been shown to have the most powerful effects on decreasing stigma, indirect contact through film and faculty/student discussion is also effective at decreasing stigma but to a lesser extent. ${ }^{25}$ Patient-centered communication courses, as well as psychiatric elective courses, can decrease stigma and teach professional interactive skills. Faculty offering mental health electives used media presentations, first-hand exposure to psychiatric patients while hospitalized, or in the classroom, and contact with mental health and neurologic disorder advocacy organizations. ${ }^{26,27}$ Experiential learning through IPPEs and APPEs where students use their knowledge and skills to directly care for patients under faculty supervision has been described as the best means of learning psychiatric and neurologic therapeutics while decreasing stigma associated with these disorders. ${ }^{20,24,28-30}$ A United Kingdom study showed only one-third of pharmacy programs offer experiential learning in psychiatry. Consequently, most pharmacy graduates in the UK reported feeling uncomfortable speaking to patients with mental illness and acknowledged deficits in how to manage common psychotropic medication-related issues. ${ }^{24}$ 


\section{American Journal of Pharmaceutical Education 2017; 81 (7) Article 5925.}

Our 2015 survey showed that pharmacy programs in the United States on the whole offer more experiential learning opportunities in psychiatry compared to pharmacy programs in the UK, but because APPEs in psychiatry and neurology are electives, most students graduate without a practice-based experience in psychiatry or neurology. Limited sites and preceptors with expertise in psychiatry and neurology are two additional reasons for a lack of IPPE and APPE experiential learning opportunities according to a 2007 survey of psychiatric pharmacy curriculum and according to comments from respondents to our 2015 survey. ${ }^{20}$ Data have been published describing the "how-to's" of developing psychiatric APPEs. ${ }^{28-30}$ These papers show how to incorporate interprofessional education while learning knowledge and skills during a psychiatric APPE, which the authors' feel is an essential component of these experiences. Resources are available for individuals interested in learning more about best practices or potential barriers for implementing psychiatric APPEs. ${ }^{31}$

Table 1 shows the mean number and types of experiential learning opportunities in psychiatry and neurology for pharmacy students. The majority of elective APPEs in neuropsychiatry are located in acute care units which may not adequately prepare pharmacists who will be primarily working with patients in the community or ambulatory care settings. Furthermore, neuropsychiatric content is generally not taught within ACPE's four required APPEs (acute care, ambulatory care, systems, and community practice). ${ }^{32}$ These core APPEs and IPPEs should include more content and experiential learning opportunities in neurology and psychiatry for several reasons: one out of every four people is diagnosed with a psychiatric and/or neurologic disorder, these disorders are chronic conditions in most cases, hands-on experience offers the best opportunity to combat stigma, and health disparities currently exist for patients with these disorders. APPEs and IPPEs that integrate a psychiatry and/ or neurology component would also meet several of the educational outcomes established by the Center for the Advancement of Pharmacy Education (CAPE) including patient-centered and population-based care, patient advocacy, interprofessional collaboration, and cultural sensitivity. ${ }^{33}$ Although exposure to individuals with neuropsychiatric disorders can be accomplished outside of IPPEs and APPEs, if merely offered as an elective didactic opportunity, only a minority of students may benefit. It should be noted that experiential learning in neuropsychiatry is part of the required experiential curriculum for medical and nursing programs in the United States. ${ }^{34,35}$ Table 2 provides a short list of places where student learning opportunities can be created in neurology and psychiatry within required ambulatory care and acute care pharmacy experiences. Information was derived from survey data, author experience, and educational literature. ${ }^{36}$

Today's pharmacists interact with individuals who have neurologic and psychiatric conditions in many settings. They are asked to provide comprehensive medication management to these patients who frequently have comorbid conditions such as diabetes, hypertension, or gastrointestinal disorders. Collaborative practice models are increasingly utilized in health systems such as the patient-centered medical home or The Veterans Health Administration Patient Aligned Care Team (PACT) to increase access to comprehensive medication management for patients. ${ }^{37}$ These settings employ pharmacist specialists who, for the most part, learned through completion of a residency, a fellowship or by practicing for several years. ${ }^{38}$ They also employ non-specialist pharmacists who practice in acute care and ambulatory care settings. ${ }^{37}$ Care models that demonstrate collaboration between pharmacist specialists and generalists are

Table 1. Advanced Practice Pharmacy Experiences (APPEs): Available Sites, Preceptors, and Placements ${ }^{\mathrm{a}}$

\begin{tabular}{lccc}
\hline Type of APPE Placement & $\begin{array}{c}\text { Number of Sites } \\
\text { (mean; median; range) }\end{array}$ & $\begin{array}{c}\text { Number of Preceptors } \\
\text { (mean; median; range) }\end{array}$ & $\begin{array}{c}\text { Number of Placements } \\
\text { (mean; median; range) }\end{array}$ \\
\hline Acute inpatient psychiatry & $2.8 ; 2 ; 0-15$ & $3.5 ; 2.5 ; 0-15$ & $19.6 ; 16 ; 0-83$ \\
Acute inpatient neurology & $0.9 ; 0 ; 0-12$ & $0.8 ; 0 ; 0-10$ & $3.8 ; 0 ; 0-23$ \\
Ambulatory psychiatry general & $1.0 ; 1 ; 0-6$ & $1.1 ; 1 ; 0-5$ & $5.3 ; 4 ; 0-43$ \\
Ambulatory neurology general & $0.2 ; 0 ; 0-2$ & $0.2 ; 0 ; 0-1$ & $1.4 ; 0 ; 0-16$ \\
Ambulatory psychiatry specialty & $0.2 ; 0 ; 0-2$ & $0.3 ; 0 ; 0-2$ & $1.8 ; 0 ; 0-18$ \\
Ambulatory neurology specialty & $0.1 ; 0 ; 0-2$ & $0.2 ; 0 ; 0-2$ & $1.3 ; 0 ; 0-26$ \\
Geriatric psychiatry & $0.5 ; 0 ; 0-10$ & $0.7 ; 0 ; 0-12$ & $3.9 ; 0 ; 0-55$ \\
Pediatric psychiatry & $0.2 ; 0 ; 0-2$ & $0.2 ; 0 ; 0-1$ & $0.7 ; 0 ; 0-12$ \\
Forensic psychiatry & $0.1 ; 0 ; 0-2$ & $0.2 ; 0 ; 0-3$ & $0.9 ; 0 ; 0-14$ \\
Substance use disorders & $0.3 ; 0 ; 0-2$ & $0.4 ; 0 ; 0-4$ & $2.6 ; 0 ; 0-18$ \\
\hline
\end{tabular}

${ }^{a}$ Table 1 displays the number of sites, preceptors and placements for each type of advanced practice pharmacy experience reported by each responding pharmacy program. The mean, median, and numerical range of responses are presented for each category 


\section{American Journal of Pharmaceutical Education 2017; 81 (7) Article 5925.}

Table 2. Creating Practice-Based Learning Opportunities in Neurology and Psychiatry for Pharmacists ${ }^{\mathrm{a}}$

\begin{tabular}{|c|c|}
\hline Institution or Organization & Practice-Based Learning Opportunity \\
\hline$\overline{\text { Academia }}$ & $\begin{array}{l}\text { Classroom, online or hybrid live/online courses } \\
\text { Clinical Practice: design IPPE and APPE } \\
\text { Research: clinical and translational science }\end{array}$ \\
\hline Administration & $\begin{array}{l}\text { P\&T, Quality improvement, safety committees, prior authorization department in health } \\
\text { plans, courts }\end{array}$ \\
\hline Forensic Centers & Penal code units at state hospitals, jail psychiatric wards \\
\hline Government & CDC, NINDS, Centers for Medicare and Medicaid, FDA, courts \\
\hline Hospitals & $\begin{array}{l}\text { Neurocritical care ICU, neurosurgery, neurology, general medicine, emergency department, } \\
\text { Acute care psychiatry }\end{array}$ \\
\hline Long-term Care/Nursing Homes & Medication reviews, gradual dose reduction of antipsychotics, drug interaction screening \\
\hline Technology Companies & Medical apps, devices, patient tools, diagnostic devices, genetic companies (Proove), etc. \\
\hline Veterans Affairs (VA) & Centers of excellence and inpatient behavioral management \\
\hline
\end{tabular}

ahttps://cpnp.org/about/public/faq

increasingly utilized to provide much needed collaborative care to patients with medical and neuropsychiatric conditions (eg, schizophrenia and cardiovascular disease). ${ }^{37} \mathrm{~A}$ recommended set of outcomes for students that could be adopted by faculty leading curriculum and assessment include:

1. Analyze the types of neurological and psychiatric emergencies and the actions necessary to improve patient outcomes (eg. prevent status epilepticus, prevent a suicide attempt).

2. Given a patient with a psychiatric or neurologic disorder, evaluate issues of social, culture, family and economics that impact access to care and engagement in treatment.

3. Analyze how pharmacodynamics, pharmacokinetics, pharmacogenomics and medicinal chemistry impact personalized care of individuals with psychiatric and neurologic disease.

4. Evaluate the role of the pharmacist as educators in prevention and recognition of psychiatric and neurologic disorders and in counseling on psychotropic and neurologic drugs.

5. Analyze and provide solutions for the multiple mechanisms that can cause harm in patients with 


\section{American Journal of Pharmaceutical Education 2017; 81 (7) Article 5925.}

psychiatric and neurologic disease (prevent drug toxicity or drug overdose).

The overarching question under consideration in this discussion is whether the current state of curricula is enough, ideal or appropriate for students who will practice as pharmacists six to 50 years hence. The likely answer to the question is "no." However, curricula are already too full, so what should faculty focus on for teaching psychiatry and neurology and how many hours of exposure is enough? Rather than focusing on how much exposure to psychiatric or neurologic topics are needed in the classroom versus experiential settings or anticipating future needs, perhaps the actual question is what do students need to know about engaging people to actively participate in their own health care. Core to our practice is the safety and well-being of an individual. The changing dynamics of health care and disease burden will continue to challenge our core mission. Providing students with an opportunity to develop skills and competencies that can be applied to preventing disease and improving a person's overall health has been endorsed by health care professional organizations such as the Association of American Medical Colleges, the Commission on Collegiate Nursing Education, AACP, and ACPE.

The American College of Clinical Pharmacy (ACCP) sought to assist pharmacy programs with making more objective curricular decisions on the breadth and depth of content based on frequency of disease, socioeconomic impact, and pharmacist involvement, thus lessening the impact of faculty preference/expertise on curricular design. To this end, ACCP's Educational Affairs Committee developed the 2016 Pharmacotherapy Didactic Curriculum toolkit, an update of the original 2009 guidance document. The committee categorized therapeutic content areas and assigned a rating from Tier 1 to 3. A "Tier 1" indicates the highest priority content as students are expected to be able to provide care to patients with these conditions upon graduation and licensure and " 3 " the lowest, which means students and residents may need to educate themselves on these conditions outside of the educational and training setting. ${ }^{19}$ Tier 1 conditions include headache, neuropathic and nociceptive pain, depressive and anxiety disorders, insomnia, and alcohol, opioid, tobacco use disorders. Tier 2 conditions consist of epilepsy including status epilepticus, Parkinson's disease, multiple sclerosis, neurocognitive disorders (dementias), stroke (listed under cardiovascular disorders), traumatic brain injury (listed under critically ill patients so no recommendation for educating students of the long-term sequelae including behavior disturbances), attention-deficit/hyperactivity disorder, bipolar disorder, obsessive-compulsive disorder, schizophrenia, substance use disorders other than the ones included in Tier 1, and post-traumatic stress disorder. Autism spectrum, eating, and personality disorders were moved to Tier 3 indicating that education on these conditions is not necessary for pharmacy students. ${ }^{19}$ This suggestion is in sharp contrast to the average number of hours recommended by CPNP members for these topics. CPNP's task force could not assess the impact of the 2009 ACCP's Pharmacotherapy Toolkit on curriculum development given neither survey asked about its use. This survey was administered prior to the publication of the 2016 update.

In our survey, the majority of respondents said that certain professional activities should be taught as part of the doctor of pharmacy curriculum; similar to the entrustable professional activities (EPAs) proposed by AACP. These included mental status examination, neurological examination, motivational interviewing, shared decision making, psychiatric rating scales, and side effect monitoring scales. Other essential skills are mental health prevention and identification of individuals in need of mental health treatment (eg, depression screening). ${ }^{8}$ It will be important for programs to identify core curriculum where these skills can be taught, opportunities for interprofessional interaction, team development, and destigmatization.

Once universal EPAs are established by AACP, they can serve as the framework for defining EPAs specific to psychiatry or neurology. At an institutional level, it will be important to define the set of skills students need to obtain during the didactic portion of their education and what additional skills are obtained through the IPPE(s) and APPE(s). This process may also help identify current gaps and allow programs to justify the need for additional psychiatric and/or neurologic pharmacy faculty.

There are many places across a curriculum where topics in neurology and psychiatry can be integrated (Table 3). Not every student is going to be exposed to every topic listed in Figures 2, 4 and 5. The important concepts for student pharmacists to ensure competency into the future are integrity, communication, working with the interprofessional team, and learning from, with, and about each other in addition to collaborating with students from other disciplines. Other neuroscience competencies essential for a general practitioner include the ability to counsel individuals and families, recognize acute neurological and psychiatric conditions that require higher levels of care, and develop treatments considering social, cultural and economic considerations of individuals. Experiential gaps in neuropsychiatry can be addressed by encouraging students to engage in extracurricular activities with local chapters of the National Alliance on Mental Illness or the Epilepsy Foundation, or national 


\section{American Journal of Pharmaceutical Education 2017; 81 (7) Article 5925.}

Table 3. Recommended Topics, Concepts and Curricular Considerations for Person-centered, Team-based Care in Neurology and Psychiatry

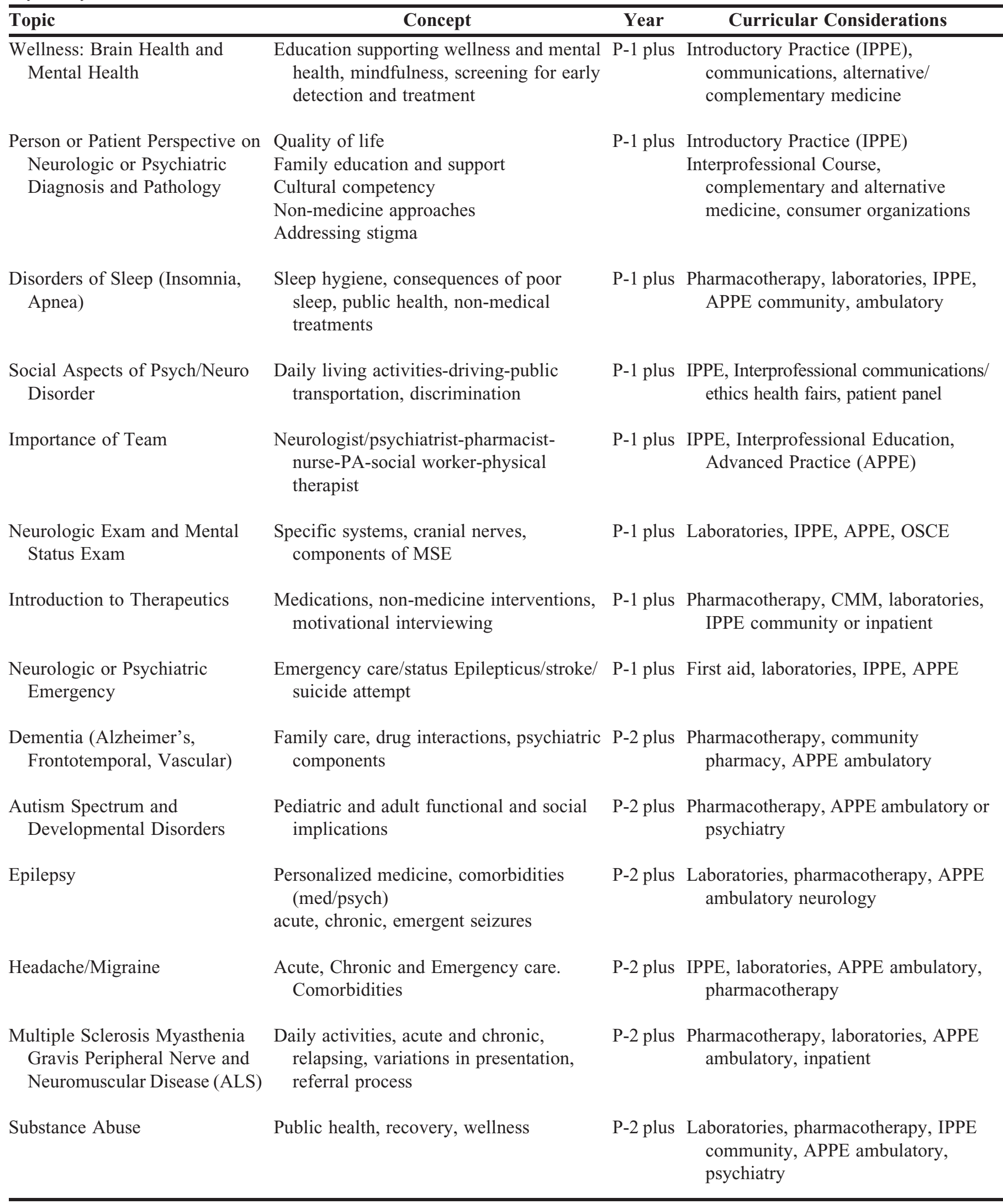




\section{American Journal of Pharmaceutical Education 2017; 81 (7) Article 5925.}

Table 3. (Continued)

\begin{tabular}{|c|c|c|c|}
\hline Topic & Concept & Year & Curricular Considerations \\
\hline Pain & Acute, chronic, non-medicine treatments & P-2 plus & $\begin{array}{l}\text { Pharmacotherapy, APPE ambulatory, } \\
\text { pain management }\end{array}$ \\
\hline $\begin{array}{l}\text { Parkinson and Psychiatric } \\
\text { Comorbidity }\end{array}$ & $\begin{array}{l}\text { Family support, limiting daily activities, } \\
\text { drug interactions, psychiatric } \\
\text { components }\end{array}$ & P-2 plus & $\begin{array}{l}\text { Pharmacotherapy, laboratories, } \\
\text { community pharmacy, APPE } \\
\text { ambulatory, neurology }\end{array}$ \\
\hline ADHD & $\begin{array}{l}\text { Developmental pediatrics, brain and } \\
\text { behavior, long-term drug efficacy and } \\
\text { safety }\end{array}$ & P-2 plus & $\begin{array}{l}\text { APPE acute care, APPE ambulatory } \\
\text { care, community pharmacy }\end{array}$ \\
\hline
\end{tabular}

Consensus recommendations from authors

involvement with the College of Psychiatric and Neurologic Pharmacists (CPNP) and with a local student chapter if available. Curriculum committee members should focus on developing learning opportunities that help students achieve knowledge and skills in areas of social, economic, cultural and personalized medicine while giving them experience with individuals with neurologic or psychiatric disease in both required and elective IPPEs and APPEs.

One of the most compelling strengths of this study is that it is the first to report objective data on clinical pharmacy program curriculum for both psychiatry and neurology in the United States. A second notable strength is our survey response rate with $56 \%$ of pharmacy programs responding and $65 \%$ of CPNP members responding. A third strength is the high percentage of board certification among member respondents signifying specialized knowledge and skills in psychiatry and neurology to inform curriculum recommendations. At the time of the survey, 652 pharmacists $(72.2 \%)$ out of the total number of 903 holding BCPP certification per the Board of Pharmacy Specialties were members of CPNP and were included in the survey if they reported an academic affiliation. $^{43}$

There are several limitations to our study. First, the initial choice of 0.1-1 hours spent teaching therapeutics topics that was included on both surveys could have led to inaccuracies in time allotted to a given topic. If $0.1-1$ hour was selected by a program or member, it was counted as 1 hour in the analysis but it may have been as short as 6 minutes of instruction time. Second, partially answered surveys were included in the analysis leading to variable denominators in calculating percentages. Third, and perhaps most significant, is the inherent potential for bias and inaccuracies with survey-based data. For example, information provided in the pharmacy program survey may not have been accurate depending upon the role of the faculty who filled out the survey and whether or not they sought out other persons (eg, experiential directors) who might be more knowledgeable regarding certain information requested.

Member survey data was weighted more heavily to those practicing in psychiatry than neurology and this likely biased the results. Of the current membership of CPNP who are BCPPs, $91.3 \%$ of the members indicate a specialty in psychiatry versus $12.8 \%$ in neurology (some members self-reported having specialties in multiple areas). This difference in percentage was also observed in the sample sent and the survey $(94.7 \%$ vs. $14.8 \%)$. From the survey results, pharmacists who taught the neurology components of the curriculum were much more likely to hold board certification in pharmacotherapy (BCPS). According to the Board of Pharmacy Specialties 2015 Annual Report, 17,711 pharmacists are BCPS. ${ }^{44}$ Only 32 respondents to our survey were BCPS, which represents less than .2\% of all pharmacists holding this board certification. Future studies may include sampling a larger number of pharmacists with a BCPS to inquire about their teaching the neurology components of the curriculum.

\section{CONCLUSION}

Psychiatric and neurologic therapeutics coursework was included in all accredited U.S. pharmacy programs that responded to our survey in 2015. A minority of programs relied on didactic lectures to deliver content with limited IPPEs and APPEs in psychiatry and neurology. Most schools offered some APPE opportunities while IPPEs in psychiatry or neurology were non-existent or underdeveloped at most programs. APPE opportunities in psychiatry outnumbered APPE opportunities in neurology by 5 to 1 . Programs relied on BCPPs to teach topics in 


\section{American Journal of Pharmaceutical Education 2017; 81 (7) Article 5925.}

psychiatry over $50 \%$ of the time while BCPSs were relied upon to teach traumatic brain injury, stroke, and pain syndromes $>50 \%$ of the time.

Psychiatry and neurology are therapeutic areas particularly well-suited to teaching person-centered, teambased care along with entrustable professional activities as required in ACPE standard 2016. Curriculum planners and educators have many opportunities to integrate neuropsychiatric content into pharmacy programs using active learning strategies such as TBL, PBL, and case conferences. Pharmacy programs should consider requiring an experiential component in psychiatry and/ or neurology at some point in the four-year pharmacy curriculum and there are opportunities to integrate these into required APPEs such as ambulatory care. Board certified academicians practicing in neurology and psychiatry concur with available studies demonstrating that firsthand experience in caring for a person with a psychiatric or neurologic disorder is the best way to teach skills, destigmatize neuropsychiatric disorders, and prepare graduates to deliver a high standard of care to the approximately $25 \%$ of the population living with a psychiatric and/or neurologic disorder.

\section{REFERENCES}

1. Grohol JM. CDC statistics: mental illness in the United States. http://psychcentral.com/blog/archives/2011/09/03/cdc-statisticsmental-illness-in-the-us/. Accessed March 26, 2016.

2. Oregon Health Science University (OHSU) Brain Institute. Disease statistics. http://www.ohsu.edu/xd/health/services/brain/incommunity/brain-awareness/brain-health/disease-statistics.cfm. Accessed March 26, 2016.

3. National Institute of Mental Health. US leading categories of diseases/disorders. http://www.nimh.nih.gov/health/statistics/ disability/us-leading-categories-of-diseases-disorders.shtml.

Accessed April 7, 2016.

4. National Institute of Mental Health. Total expenditures for the five most costly medical conditions (1996 vs 2006). http://www.nimh.nih. gov/health/statistics/cost/total-expenditures-for-the-five-most-costlymedical-conditions-1996-vs-2006.shtml. Accessed April 7, 2016.

5. Insel T. Assessing the state of America's mental health system. Testimony before the Committee on Health, Education, Labor, and Pensions, US Senate, 2013. http://www.help.senate.gov/imo/media/ doc/Insel.pdf. Accessed April 7, 2016.

6. Hawkins K, Wang S, Rupnow M. Direct cost burden among insured US employees with migraine. Headache. 2008;48(4): 553-563.

7. Chisholm D, Sweeny K, Sheehan P, et al. Scaling up treatment of depression and anxiety: a global return on investment analysis. Lancet Psychiatry. 2016;3(5):415-424.

8. Siu AL, US Preventive Services Task Force, Bibbins-Domingo K, et al. Screening for depression in adults: US Preventive Services Task Force recommendation statement. JAMA. 2016;315(4):380-387. 9. Siu AL, US Preventive Services Task Force, et al. Screening for depression in children and adolescents recommendation statement. Pediatrics. 2016;137(3):e20154467.
10. American Association of Colleges of Pharmacy. Academic Pharmacy's vital statistics. http://www.aacp.org/about/Pages/ Vitalstats.aspx. Accessed May 26, 2016.

11. Kwon J, Ledvina D, Newton M, Green MR, Ignoffo R. Oncology pharmacy education and training in the United States schools of pharmacy. Curr Pharm Teach Learn. 2015;7(4):451-457.

12. Murphy JE, Green JS, Adams LA, Squire RB, Kuo GM, McKay A. Pharmacogenomics in the curricula of colleges and schools of pharmacy in the United States. Am J Pharm Educ. 2010;74(1): Article 7.

13. Prescott WA, Dahl EM, Hutchinson DJ. Education in pediatrics in US colleges and schools of pharmacy. Am J Pharm Educ. 2014;78(3):Article 51.

14. American Society of Consultant Pharmacists. Geriatric Pharmacy Curriculum Guide, $3^{\text {rd }}$ ed. Alexandria, VA: ASCP; 2015. 15. Jungnickel PW, DeSimone EM, Kissack JC, et al. Report of the AACP special committee on substance abuse and pharmacy education. Am J Pharm Educ. 2010;74(10):S11.

16. Goetz CG. Historical interfaces between American neurology and psychiatry. In Jeste DV, Friedman JH, eds. Psychiatry for Neurologists. New York, NY: Humana Press, Springer;2006. 17. White PD, Rickards H, Zeman AZ. Time to end the distinction between mental and neurological illnesses. BMJ 2012;344:e3454. 18. Diagnostic and Statistical Manual of Mental Disorders. $5^{\text {th }}$ ed. Arlington, VA: American Psychiatric Press; 2013.

19. American College of Clinical Pharmacy. The 2016 ACCP Pharmacotherapy Didactic Curriculum Toolkit. http://www.accp. com/docs/positions/misc/Toolkit_final.pdf. Accessed November 4, 2016.

20. Cates ME, Monk-Tutor MR, Drummond SO. Mental health and psychiatric pharmacy instruction in US colleges and schools of pharmacy. Am J Pharm Educ. 2007;71(1):Article 4.

21. Ofstad W, Brunner LJ. Team-based learning in pharmacy education. Am J Pharm Educ. 2013;77(4):Article 70.

22. Bell JS, Aaltonen SE, Airaksinen MS, et al. Determinants of mental health stigma among pharmacy students in Australia, Belgium, Estonia, Finland, India, and Latvia. Int J Soc Psychiatry. 2010;56(1):3-14.

23. Jacoby A, Snope D, Baker GA. Epilepsy and social identity: the stigma of a chronic neurological disorder. Lancet. 2005;4(3):

171-178.

24. Rutter P, Taylor D, Branford D. Mental health curricula at schools of pharmacy in the United Kingdom and recent graduates' readiness to practice. Am J Pharm Educ. 2013;77(7):Article 147. 25. Nguyen E, Chen TF, O'Reilly CL. Evaluating the impact of direct and indirect contact on the mental health stigma of pharmacy students. Soc Psychiatry Psychiatr Epidemiol. 2012;47(7): 1087-1098.

26. Dipaula BA, Qian J, Mehdizadegan N, Simoni-Wastila L. An elective psychiatric course to reduce pharmacy students' social distance toward people with severe mental illness. Am J Pharm Educ. 2011;75(4):Article 72.

27. Gable KN, Muhlstadt KL, Celio MS. A mental health elective to improve pharmacy students' perspectives on mental illness. Am J Pharm Educ. 2011;75(2):Article 34.

28. Goldstone LW, Cooley J. An interprofessional psychiatric advanced pharmacy practice experience. Am J Pharm Educ. 2013;77(6):Article 129.

29. Caballero J, Marino J, Morales M, Hinkes R. Development of a collaborative psychiatric advanced pharmacy practice experience. Ment Health Clin. 2013;2(10):325-328. 


\section{American Journal of Pharmaceutical Education 2017; 81 (7) Article 5925.}

30. Ott CA. Advanced practice pharmacy experiences (APPE) in psychiatric pharmacy. Ment Health Clin. 2013;2(10):319-321.

31. Tillery EE. Toolbox: tips for establishing psychiatric pharmacy practice sites. Ment Health Clin. 2014;4(6):265.

32. Accreditation Council on Pharmacy Education (ACPE). https:// www.acpeaccredit.org/deans/2016StandardsRevision.asp. Accessed March 16, 2016.

33. Medina MS, Plaza CM, Stowe CD, et al. Center for the Advancement of Pharmacy Education 2013 educational outcomes. Am J Pharm Educ. 2013;77(8):Article 162.

34. American Association of Colleges of Nursing. Curriculum Guidelines. http://www.aacnnursing.org/Education-Resources/ Curriculum-Guidelines.

35. Association of American Medical Colleges. Percentage of medical schools with separate required clerkships by discipline. https://www.aamc.org/initiatives/cir/406450/05a.html.

36. Neuropsychiatric pharmacy FAQ. https://cpnp.org/about/public/ faq. Accessed March 16, 2016.

37. Goldstone LW, DiPaula BA, Caballero J, Park SH, Price C, Slater MZ. Improving medication-related outcomes for patients with psychiatric and neurologic disorders: value of psychiatric

pharmacists as part of the health care team. Mental Health Clinician 2015;5(1):1-28.
38. Stoner SC, Ott CA, DiPaula BA. Psychiatric pharmacy residency training. Am J Pharm Educ. 2010;74(9):Article 163.

39. Interprofessional Education Core Competencies for interprofessional collaborative practice: 2016 update. http://www. asha.org/uploadedFiles/Interprofessional-Collaboration-CoreCompetency.pdf. Accessed March 16, 2016.

40. Ten Cate O. Nuts and bolts of entrustable professional activities. J Grad Med Educ. 2013;5(1):157-158.

41. American Association of Medical Colleges. Core entrustable professional activities for entering residency. Curriculum developers' guide. https://members.aamc.org/eweb/upload/core $\%$ 20EPA\%20Curriculum\%20Dev\%20Guide.pdf. Accessed February 14, 2016.

42. Treiman D, Meyers PD, Walton NY, et al. A comparison of four treatments for generalized convulsive status epilepticus for the Veterans Affairs status epilepticus cooperative study group. $N$ Engl $J$ Med. 1998;339(12):792-798.

43. Johnson L, Adams Becker S, Cummins M, Estrada V, Freeman A, Hall C. NMC Horizon Report: 2016 Higher Education Edition. Austin, Texas: The New Media Consortium; 2016.

44. Board of Pharmacy Specialties 2015 Annual Report. http:// mobile.epaperflip.com/?docid $=$ afe5e1de-a5ea-44a2-acb3a5d300fa 75a4\&page $=1 \#$ page $=0$. 